\title{
BIOMASS FROM WOOD PROCESSING INDUSTRIES AS AN ECONOMICALLY VIABLE AND ENVIRONMENTALLY FRIENDLY SOLUTION \\ ${ }^{1}$ I. Kiss, ${ }^{2}$ V. Alexa, ${ }^{3} \mathrm{~J}$. Sárosi \\ ${ }^{1-2}$ University Politehnica Timişoara, Faculty of Engineering Hunedoara, Department of Engineering and Management, 5, Revolutiei, 331128, Hunedoara, Romania e-mail:imre.kiss@fih.upt.ro, vasile.alexa@fih.upt.ro, ${ }^{3}$ University of Szeged, Faculty of Engineering, Moszkvaikrt. 9, 6725 Szeged, Hungary e-mail: sarosi@mk.u-szeged.hu
}

\begin{abstract}
Biomass is seen as an economically viable and environmentally friendly solution to energy generation. Biomass is a financially viable investment as well as being environmentally friendly. The development and implementation of biomass technologies could bring many environmental, energetically and economic benefits, solving important problems such as waste disposal and renewable energy supply. The different countries clearly have chosen very different approaches in developing and deploying various bio-energy options. Partly this is caused by the natural conditions (type of resources and crops, climate) and the structure of the energy system, and also by the specific political priorities linked to the agricultural and forestry sectors in those countries. Romania has a significant potential in organic waste, including waste generated in forestry sector, agro-food industry or municipal biodegradable wastes. Biomass is an emerging renewable fuel that can help to heat homes and buildings at lower impact to the environment and lower costs than fossil fuels. The fuel (usually in the form of biomass pellets) is made from sustainable materials, such as wood, which is easily replaced and in abundance, at a relatively cheap price. As people are becoming more and more conscious about their individual impact on the environment and looking into greener, more efficient alternatives, biomass is slowly becoming one of the nation's favorite renewable heat technologies. Actually, sawdust as by-product from wood sawing process, doesn't have much application because of its low burning efficient. However, by pressing the saw dust into pellets, it becomes a kind of high quality biofuel product - sawdust pellets or wood pellets.
\end{abstract}

Keywords: sawdust pellets, pelletization process, woody biomass resources

\section{INTRODUCTION}

Wood pellets are a form of biomass energy that is very popular for the international market either for electricity or heat generation sector. Increasingly needs wood pellets are expected to be increased, or 2024 global production of wood pellets will be 50 million tons. Some of the recent predictions suggest that biomass energy is likely to make up one third of the total world energy mix by 2050 .

Romania have an immense bioenergy potential due to plentiful supply of diverse forms of biomass wastes such as the woody biomass which is a good energy resource due to presence of large number of forests in Romania. In addition, the presence of a large number of wood processing industries also generates significant quantity of wood wastes. Wood wastes generally are concentrated at the processing factories, e.g. plywood mills and sawmills, but the wastes generated from wood processing industries varies from one type industry to another depending on the form of raw material and finished product (sawmilling, plywood, wood panel, building component, furniture, flooring etc.). Romania, with its abundant bioenergy resources, can hold a strategic position in the global biomass energy atlas. Unfortunately, recycling of wood wastes is not done by all wood industries, particularly small to medium scale wood industries.

Biomass has rapidly become a vital part of the global renewable energy mix, counting traditional biomass, large hydropower, and "new" renewables (small hydro, modern biomass, wind, solar, geothermal, and biofuels). Biomass power is the largest source of renewable energy as well as a vital part of the waste management infrastructure. Biomass may be used for energy production at different scales, including large-scale power generation or small-scale thermal heating projects. Traditional biomass is primarily used for cooking and heating. The use as fuel of some of the wood wastes (like sawdust and chips) is usually practiced in large and modern establishment (Fig. 1). [1-7], [9], [12], [15] 


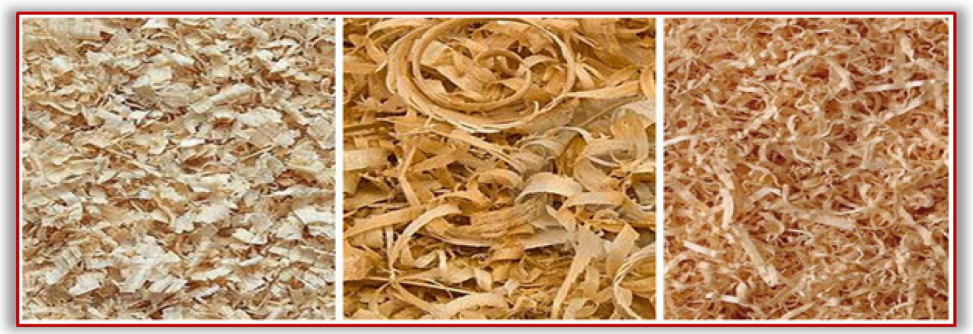

Figure 1. Wood wastes as sawdust

Biomass energy resources are readily available in rural and urban areas. Biomass has been a primary source of energy for many years, used for domestic heating and industrial cogeneration. Biomass-based industries can provide appreciable employment opportunities and promote biomass re-growth through sustainable land management practices. Wood has been the dominant fuel and has a long tradition in Romanian rural areas based on its availability, sustainability, environmentally friendly and renewable natural resource characteristics. Romania has a significant forestry potential of wood and plant to support the production of pellets and briquettes in terms of quality and protection to meet the requirements and standards $[16,17]$.

\section{MAJOR SOURCES OF WOODY BIOMASS DESTINED FOR PELLETS PRODUCTION}

Some of the major sources of woody biomass destined for pellets production are being discussed in the following paragraphs.

The major biomass resources in Romania include the following:

- firewood and woody biomass residues from forests harvesting operations (may occur as thinning in young stands or cutting in older stands for timber);

- woodprocessing residues from wood and furniture industries (sawmilling, plywood, wood panel, building component, furniture, flooring etc.);

- agricultural crops and agro-processing residues;

- urban wood wastes (collected woody materials after a construction or demolition projects, rejected wood pallets and any other construction and demolition wastes made from timber).

Romania's vast biomass potential has been partially exploited through the use of traditional as well as more advanced conversion technologies for biogas, power generation, and biofuels. Wood-related industries are the major potential biomass energy sources. The agricultural crops and agro-processing residues are insignificant, despite the fact that an increased potential exist in Romania.

Sawdust is by-product from wood sawing process. Actually, sawdust doesn't have much application because of its low burning efficient. However, by pressing the saw dust into pellets, it becomes a kind of high quality biofuel product - sawdust pellets or wood pellets (Fig. 2). [8, 10, 11]

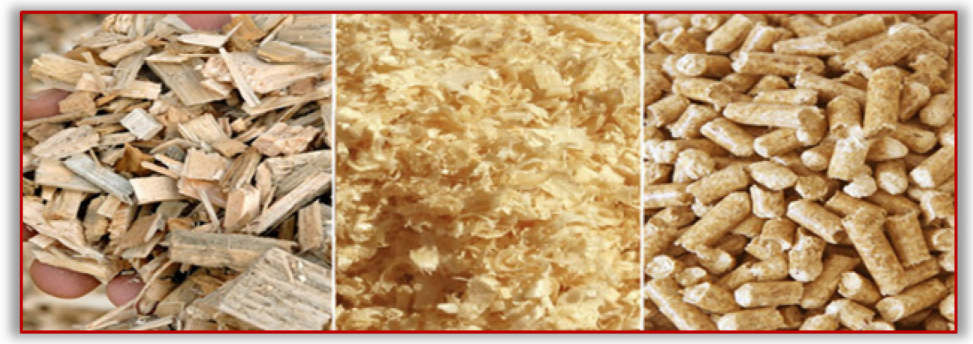

Figure 2. Sawdust and pellets 
Pellets and briquettes production increased in Romania mostly after the country inclusion in EU. This was and still is mostly related with the new markets in Europe. Currently, there are many pellet producers in Romania, but information about their production capacities is scarcely accessible. In general, most of the production of large companies is sold on western European markets. Small producers sell also on the Romanian market in the limit of their stocks (most of the production is realized from wood processing residues), based on pre-established contracts (Fig. 3). [14]
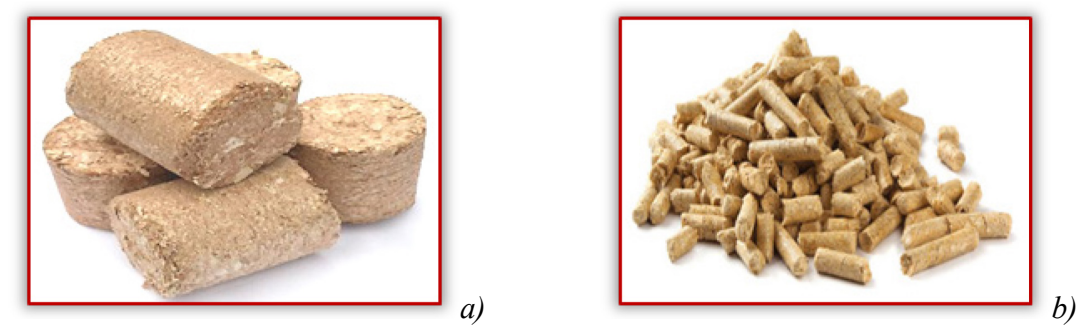

Figure 3. solid fuel by woods. a) wood briquettes; b) Wood pellets

The regular geometry and small size of biomass pellets allow automatic feeding with very fine calibration.High density of pellets also permits compact storage and rational transport over long distance. Pellets are extremely dense and can be produced with a low moisture content that allows them to be burned with very high combustion efficiency.

\section{PELLET PRODUCTION AND REQUIREMENTS}

Over the last decade there have been two major factors that have been driving the growth of the pellet fuel market. The first is the consistent rise in the cost of fossil fuels and price instability, and the second is the increased attention given to the effects of using fossil fuels such as oil and gas on the environment. Other factors that support the case for pellets is that they are a fuel that can be produced locally, from local wood and biomass materials.

Pellets have very similar combustion results to most wood pellets. The other main reasons for pellets over logs are that pellets burn much more efficiently. This means pellets produce less ash, less smoke and more heat. Also pellets have a uniform size, shape, density and moisture content. These consistent qualities make it possible to design highly automated combustion systems such as modern wood pellet stoves and boilers. One of the reasons pellet fuel is so popular is pellets have moisture content below $10 \%$. This enables the pellets to burn very efficiently, and produce virtually no smoke during combustion. Pellet production is a high temperature process. The right moisture content will produce the best quality pellets, reduce energy consumption and reduce pellet mill downtime.

In pellet production every raw material behaves differently, and some materials produce quality pellets easier than others. Depending on the equipment used, the composition of the raw material may need to be changed to produce quality pellets at a reasonable productivity. Changing the composition can include adjusting particle size or moisture content. However, it may also include adding binders and lubricants to help produce higher quality fuel pellets.

Temperature is a key requirement in pellet production. Unless a certain temperature is reached in the pellet mill natural lignin will not melt. It is not possible to produce some biomass pellets for example wood pellets without sufficient heat. However, if the temperature is too high this can damage the pellet mill.

\section{BIOMASS PELLETIZATION PROCESS - AN OVERVIEW OF THE TECHNOLOGY}

Woody biomass is the most common and popular biomass of the biomass pelletisation which is a standard method for the production of high density, solid energy carriers from biomass. Pellets are manufactured in 
several types and grades as fuels for electric power plants, homes, and other applications. Pellet-making equipment is available at a variety of sizes and scales, which allows manufacture at domestic as well industrial-scale production. Commercial pelletizing equipment's are widely available across the globe.

The biomass pelletization process consists of multiple steps including raw material pre-treatment, pelletization and post-treatment. The first step in the pelletization process is the preparation of the raw materials which includes selecting a feedstock suitable for this process, its filtration (to remove unwanted materials like stone, metal, etc.), and adequate storage, in such a manner that it is away from impurities and moisture.

Raw materials commonly used are sawdust, wood shavings and wood wastes, but also agricultural residues can be used. In cases where there are different types of feedstock, a blending process is used to achieve consistency. If the pellet size is too large or too small, it affects the quality of pellet and in turn increases the energy consumption. Therefore the particles should have proper size and should be consistent. Size reduction is done by grinding using a hammer mill. Before feeding biomass to pellet mills, the biomass should be reduced to small particles (Fig. 4).

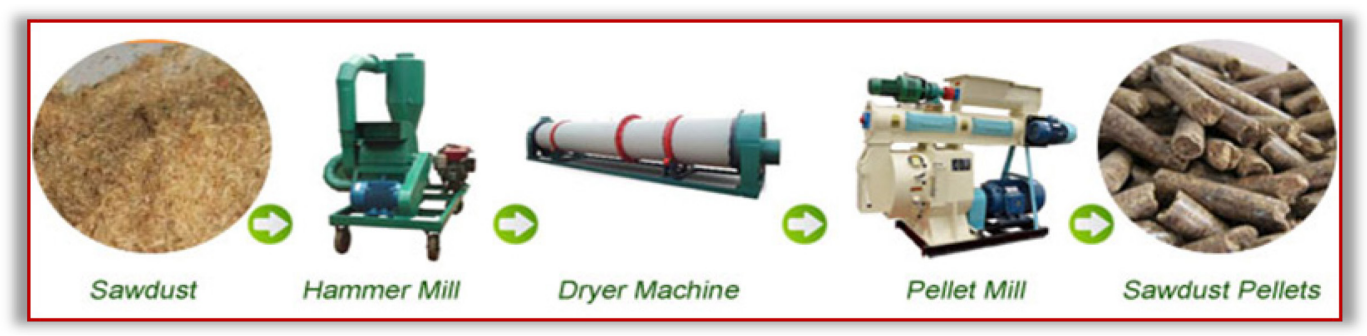

Figure 4.Schematic of pelletization of woody biomass

Most wood pellets are manufactured from clean sawdust and wood chips: waste products from lumber and other wood industries. The raw materials may be green, or freshly cut, may be partial dry or even kiln dried. By processing these raw materials all in the same way, the end product has consistent moisture content, heat value, ash content, and burn characteristics.

Some of the raw material may be sawdust, wood chips, lumber mill scrap, and even full trees unsuitable for lumber. The appearance of quality wood pellets is as varied as the many different species of trees. While a spectrum of colors is perfectly natural, wood pellets should generally not be darker than a cup of black coffee. An excessively dark color may indicate that bark was mixed into the manufacturing process, and those pellets will likely have high ash content (Fig. 5).

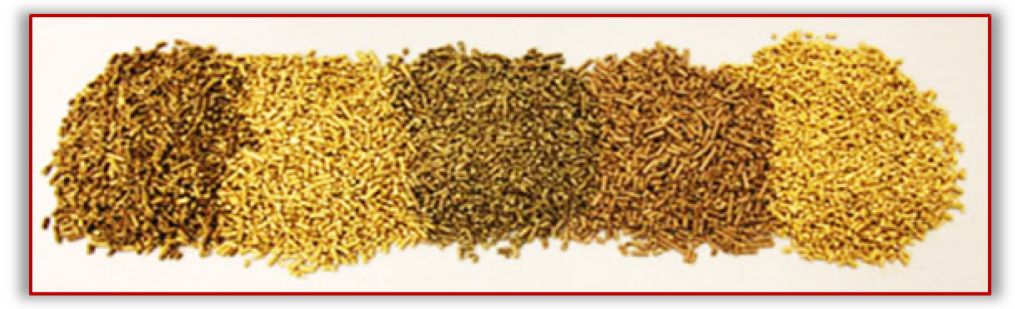

Figure 5.Spectrum of colors of pellets

Drying increases the efficiency of biomass and it produces almost no smoke on combustion. Rotary drum dryer is the most common equipment used for this purpose. In fact, the drying process is the most energy intensive process and accounts for about $70 \%$ of the total energy used in the pelletization process. The moisture content in biomass can be considerably high and are usually up to $50-60 \%$ which should be reduced to 10 to $15 \%$. It should be noted that the feedstock should not be over dried, as a small amount of moisture helps in binding the biomass particles. 
The next and the most important step is the effective pelletization process where the biomass is compressed throughof fixed diameter's holes and is passes under high pressure. The resulted high temperature causes the lignin and resins present in biomass to soften which acts as a binding agent between the biomass fibers. This way the biomass particles fuse to form pellets.

Binders or lubricants may be added in some cases to produce higher quality pellets, increasing their density and durability. Wood contains natural resins which act as a binder and, similarly, sawdust contains lignin which holds the pellet together. However, agricultural residues do not contain much resins or lignin, and so a stabilizing agent and/or natural additives needs to be added in this case, depending on biomass composition.

Due to the friction generated in the compression process, excess heat is developed. Thus, the pellets are very soft and hot (about 70 to $90^{\circ} \mathrm{C}$ ). It needs to be cooled and dried before its storage or packaging. Additional, the pellets may then be passed through a vibrating screen to remove fine materials.

The characteristics of biomass will determine the production processes including the equipment and characteristics of the wood pellets. The rate of production and electrical energy used in the pelletization of biomass are strongly correlated to the raw material type and processing conditions such as moisture content and feed size.

The heating or calorific value is a key factor when evaluating the applicability of a combustible material as a fuel. The heating value of wood and wood waste depends on the species, parts of the tree that are being used (core, bark, stem, wood, branch wood, etc.) and the moisture content of the wood. In practice, the moisture content of wood during logging is about $50 \%$. Depending on transportation and storing methods and conditions it may rise to $65 \%$ or fall to some $30 \%$ at the mill site. The moisture content of the wood waste in an industry depends on the stage where the waste is extracted and whether wood has been dried before this stage.

\section{CONCLUSIONS}

Because of the availability of raw materials is one of the key success factors in the business of wood pellets, so it needs special attention of its own. Therefore, wood sawmill wastes and wood processing wastes could be used for wood pellets manufacturing. Good forest management service that will produce a sustainable supply of raw materials.

Biomass resources, particularly residues from forests, wood processing, agricultural crops and agroprocessing, are under-utilized in Romania. There is an urgent need to utilize biomass wastes for commercial electricity and heat production to cater to the needs of the industries as well as urban and rural communities. Biomass technologies which are at present widely used in Romania are need to be improved towards best practice by making use of the latest trends in the biomass energy sector. Therefore, is needed to implement the latest waste-to-energy technologies to tap the unharnessed potential of biomass resources. The development of efficient biomass handling technologies, improvement of agro-forestry systems and establishment of small and large-scale biomass-based power plants can play a major role in rural development.

Wood Pellets are mainly made of sawdust, and that sawdust is the byproduct of wood working factories, lumberyards, and sawmills. This means they are a recycled, reclaimed product, and that is good for the environment.

The wood pellets can be used industrially or domestically, by anyone who wants to optimize heating costs and increase comfort level. [13] Overall, the wood pellets are:

clean and easy to transport, distribution and storage,

a sustainable, reliable and renewable energy source,

low priced,

easy to handle, convenience transport,

high efficiency and energy saving, good quality,

a competitive performance level in all stages of production, transport, storage and end use,

an easy way to reduce electricity consumption, 
» environmentally clean, i.e. when burnt the ash produced can be used in the garden as a fertilizer. Biomass pellets are a popular type of biomass fuel, generally made from wood wastes, agricultural biomass and forestry residues. In addition to savings in transportation and storage, pelletization of biomass facilitates easy and cost effective handling.Biomass is seen as an economically viable and environmentally friendly solution to energy generation. Biomass is a financially viable investment as well as being environmentally friendly.

Wood pellets have only become an important part of this boom in the past few years. Owners of large coal-fired power stations in Europe started searching for a way to fulfill the new regulations and to find a solution for the declining economic relevance of traditional coal-fired power stations due to their high carbon dioxide emissions. The answer was to give the old dirty giants a green coat of paint by "co-firing" regular coal power plants with wood pellets. The idea of using wood as a renewable source was backed by environment organizations. More recent pellet investment projects as well as facilities currently under construction show that the production of wood pellets is being outsourced by the energy firms to companies specialized in wood pellet production. These firms are 100-percent focused on sourcing the raw material, operating the wood pellet production plant and handling the logistics for transporting the renewable resource.

\section{REFERENCES}

[1.] Green Energy in Romania - Current situation and development perspectives (http://oldrbd.doingbusiness.ro)

[2.] A potential renewable energy resource development and utilization of biomass energy, FAO Document Repository (http://www.fao.org/documents/en/)

[3.] Romania Biomass and Biogas Energy Market 2013 - 2018 (http://renewablemarketwatch.com)

[4.] Overview and status of Renewable Energy Technologies (RET) in Romania, TU Bergakademie Freiberg, 2013

[5.] Evaluating Renewable Energy Policy: A review of criteria and indicators for assessment, Report of International Renewable Energy Agency (IRENA), 2014

[6.] Mario Ragwitz\& co.: Shaping an effective and efficient European renewable energy market, European Research Project, Fraunhofer Institute for Systems and Innovation Research, Karlsruhe, 2012

[7.] Monitoring and evaluation of the RES directives implementation in EU27 and policy recommendations for 2020, Reference Document on Renewable Energy Sources Policy and Potential, 2009 (http://www.cres.gr/res2020/)

[8.] New energy externalities development for sustainability (http://www.needs-project.org/)

[9.] Monitoring and Evaluation of the RES directives implementation in the EU27 and policy recommendations for 2020 (http://www.res2020.eu/)

[10.] My wood pellet solution: Wood pellet central-heating solution for homeowners and small industry (http://www.mywoodpelletsolution.com/overview/)

[11.] What is the best home heating energy investment? (http://www.mywoodpelletsolution.com/category/news/)

[12.] Components of wood pellet heating systems http://www.mywoodpelletsolution.com/category/system_components/)

[13.] The benefits of using wood pellets (http://woodypellets.eu/wood-pellets.html)

[14.] S. Borz, R. Derczeni, B. Popa, M-D. Nita, Regional profile of the biomass sector in Romania, Brasov, 2013 (http://www.foropa.eu/files/country_reports/country\%20report\%20romania.pdf)

[15.] Report of Romanian Pellets And Briquettes Association, The characteristics and potential of the wooden pellets and briquettes, 2014

[16.] I. Kiss, J. Sárosi,V. Alexa, About the wood sawdust - One of the most important renewable energy sources, Annals of Faculty Engineering Hunedoara - International Journal of Engineering, Fascicule 1/2016, 215-220

[17.] I. Kiss, V. Alexa, S. Ratiu, V. Cioata, About the sawdust briquetting as sustainable solution for the environment preserving ecosystems, Vth International Conference Industrial Engineering and Environmental Protection (IIZS 2015), 2015, Zrenjanin, Serbia, 63-68

[18.] S. Zafar, Biomass pelletization process,Agricultural Residues, Biomass Energy, 2014, (http://www.bioenergyconsult.com) 